\title{
Electrogeneration and Characterization of Poly(3-methylthiophene)
}

\author{
José Vicente Sanchez, Raquel Diaz, ${ }^{*}$ Pilar Herrasti, and Pilar OCON ${ }^{\dagger}$ \\ Departamento de Quimica Física Aplicada, Universidad Autónoma de Madrid, Madrid 28049, Spain \\ *Departamento de Física Aplicada, Universidad Autónoma de Madrid, Madrid 28049, Spain
}

(Received December 19, 2000; Accepted April 13, 2001)

\begin{abstract}
Results for a conducting polymer poly(3-methylthiophene) are presented with demonstration that the electrochemical deposition proceeds favourably through $3 \mathrm{D}$ instantaneous nucleation and growth. The polymer film is insulating at sufficiently negative $0.1 \mathrm{~V}$ or positive $1.6 \mathrm{~V}$ electrochemical potentials in propylene carbonate $+\mathrm{LiClO}_{4}$ solution. When the solution was $\mathrm{H}_{2} \mathrm{SO}_{4}$ the film was insulating in $0.5 \mathrm{~V}$ or $1.1 \mathrm{~V}$. The macrogrowth occurred in three dimensions and showed disordered rough structures. According to the results for $t<1 \mathrm{~s}$ the fractal dimension $D_{\mathrm{s}}=2.5$ was obtained and for $t>1 \mathrm{~s}$ this parameter was 2.0. The band gap energy of these material is $\approx 1 \mathrm{eV}$ characteristic for the polymer materials in oxidized state. This films have a lot of free charge carriers and this characteristic confers conductive properties to the material.
\end{abstract}

KEY WORDS Conducting Polymers / Electropolymerization / Fractal Dimension / Band Gap /

The modern era of conducting polymers began in 1977 when Heeger and MacDiarmid discovered that the doping of polyacetylene increases its electronic conductivity by a factor of $10 .^{1-3}$

In the last few years great interest has developed the last few years in the electrochemical study of conducting polymers such as polyaniline, ${ }^{4}$ polypyrrole, ${ }^{5}$ and polythiophene. ${ }^{6}$ The properties and structures of prepared films depend on the kind of monomer used for the polymerization as well as the experimental conditions used in their preparation, thus, polymer films with a particular desired property can be obtained. ${ }^{7}$ Polythiophene and its derivatives represent a class of organic conducting polymers, which are of great interest for some reasons. First, their electrical conductivity can be varied over twelve orders of magnitude by doping and, then, showing great chemical and electrochemical stability against moisture and oxygen.$^{8-13}$ Many of their potential applications can only be achieved if their stability is enough within a to hostile environment. ${ }^{14}$

The main feature of the conductive organic polymers such as polytiophene and polypyrrole is that both contain an extended electron structure through their configuration. These polymers are generally insulators or semiconductors in their undoped state but can be made conductive when they are subjected to a doping process. They are highly conductive in an oxidized state. The conductance process in these polymers is believed to take place by electron delocalisation. ${ }^{15}$ A correlation between the degree of oxidation and the electronic and ionic conductivities was found by Juttner et al. ${ }^{16}$

Electrochemically synthesised polymers show higher conducting properties than the same polymers synthe- sised by any other way. These properties give the materials some application as rechargable batteries, ${ }^{17,18}$ electrochromic devices, ${ }^{19}$ energy storage, ${ }^{20}$ and, recently, their use in the biomimicking process. ${ }^{21}$

A high conductivity for the polymers appears necessary in order to ensure fast and efficient electron transfer and, on the other hand, it seems reasonable to assume that a link exists between conductivity and electrochemical stability. The electrochemical deposition of some polythiophenes was reported by Hillman et $a l .{ }^{22}$ They found that the electrodeposition of conducting polymers is similar to that of metal deposition in which proceeds through a nucleation and growth pathway.

The present paper reports the syntheses and properties of poly(3-methylthiophene) (P3MT) in an organic medium, propylene carbonate, by potentiostatic and potentiodynamic method. The potentiostatic current transient was analysed with the purpose of studying the coating growth kinetics. The macrogrowth occurring with rough structure was studied and the fractal dimension was determined. Changes in the P3MT conducting properties and morphology were found, under different experimental electrodeposition conditions. Optical properties were found by transmittance and reflectance measurements for the films grow on Indium Tin Oxide electrodes. Band gap and electrical properties were also determined.

\section{EXPERIMENTAL}

The electrochemical measurements were carried out in a three electrode cell using graphite, Au or ITO elec-

†To whom correspondence should be addressed (E-mail: pilar.ocon@uam.es). 
trode as working electrode. Gold or platinum plates were used as counter electrode and pseudoreference of $\mathrm{Ag}$ or calomel electrode as reference electrode. The polymerization solutions were prepared by dissolving 3-methyltiophene (3MT) $0.1 \mathrm{M}$ in propylene carbonate $(\mathrm{PC})$ and $0.5 \mathrm{M} \mathrm{LiClO}_{4}$. The monomer was purified by vacuum distillation. Conventional voltammetry and potentiostatic current transient measurements were performed in a three-compartment electrochemical cell. The electrochemical equipment consisted of a Versa/ Start II potentiostat.

In situ resistance measurements were performed by the procedure of Contractor et al. ${ }^{23}$ It consists of two parallel gold wires very closely aligned. The polymer layer is grown out simultaneously on both wires. One of the wires is then used for potentiostatic control of the polymer and voltage drop in the polymer is measured using the second wire. The polymer is transferred to the blank solution $\left(1 \mathrm{M} \mathrm{H}_{2} \mathrm{SO}_{4}\right)$ under potentiostatic control then, a current flows across the polymer/electrolyte interface. This current reaches a steady-state value, so, we can obtain the resistance of the polymer from the relation between the current in steady-drop and the applied voltage. This voltage $\mathrm{V}$ is measured between both electrodes. ${ }^{24}$

Conventional voltammetry and potentiostatic current transient measurement in the diffusion-controlled regime were performed in a three-compartment electrochemical cell. The electrolyte solution for measurement in diffusion-controlled regime was $5 \mathrm{mM}$ $\mathrm{K}_{4}\left[\mathrm{Fe}(\mathrm{CN})_{6}\right]+5 \mathrm{mM} \mathrm{K}_{3}\left[\mathrm{Fe}(\mathrm{CN})_{6}\right]$ in $0.5 \mathrm{M} \mathrm{NaNO}_{3}$. All the experiments were performed at room temperature. The surface structure of the resulting polymer film (P3MT) was monitored on a SEM 501 Philips microscope. Optical measurements were carried out on a Cary 17D spectrophotometer.

\section{RESULTS AND DISCUSSION}

\section{Voltammetric Data}

The polymer coating formation can be followed by cyclic voltammetric, starting with the working electrode immersed in $0.1 \mathrm{M} 3 \mathrm{MT}$ acetonitrile solution, from $-1.0 \mathrm{~V}$ to $+1.3 \mathrm{~V}$ at scanning rate, $v=0.05 \mathrm{Vs}^{-1}$ (Figure 1). When the potential exceeds $+0.1 \mathrm{~V}$, an increase in the anodic current is observed followed by a current plateau which extends up and an anodic hysteresis loop display, which resembles that usually found in electrochemical reaction involving the nucleation and growth of the new phase. Subsequently the potential cycling produces the change of the anodic and cathodic currents, and the electrode is covered with a uniform insoluble and adherent deposit. The cyclic

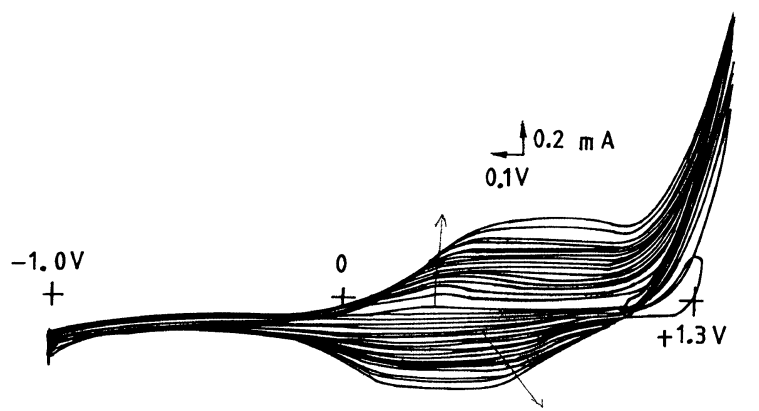

Figure 1. Cyclic voltammetric curves for the deposition of P3MT on Au electrode from $0.1 \mathrm{M} 3 \mathrm{MT}+0.1 \mathrm{M} \mathrm{LiClO}_{4}$ in acetonitrile in the potential range of $-1.0 \mathrm{~V}$ to $1.3 \mathrm{~V}$ at scan rate $=$ $0.05 \mathrm{~V} \mathrm{~s}^{-1}$.

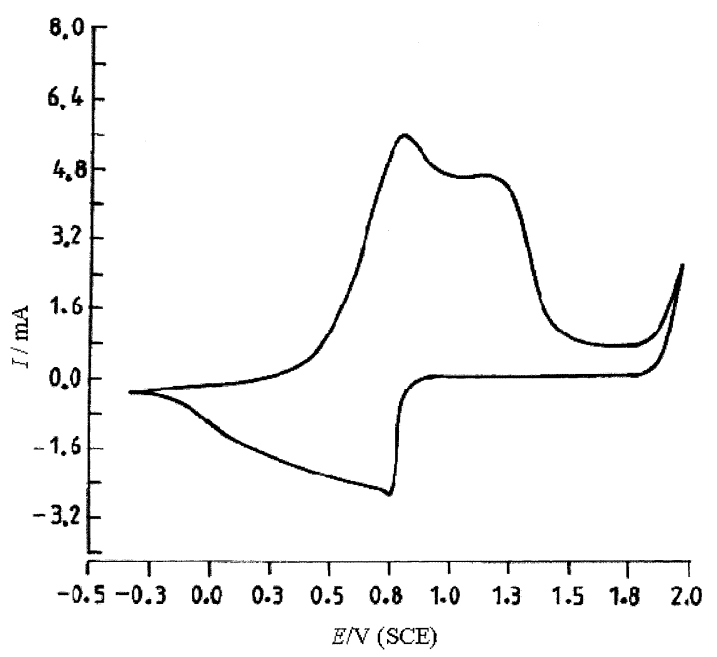

Figure 2. Cyclic voltammogram of $\mathrm{P} 3 \mathrm{MT}$ after 20 cycles, in $1 \mathrm{M} \mathrm{H}_{2} \mathrm{SO}_{4}$ at $25^{\circ} \mathrm{C}$. Scan rate $=0.05 \mathrm{~V} \mathrm{~s}^{-1}$.

voltammogram in a free-monomer $1 \mathrm{M} \mathrm{H}_{2} \mathrm{SO}_{4}$ solution. Figure 2 shows two main peaks in the positive cycle $0.8 \mathrm{~V}$ and $1.2 \mathrm{~V}$ and one reduction peak in the negative scan. When the anodic potential reaches values higher than $2.0 \mathrm{~V}$ the polymer film undergoes slow decomposition and oligomeric species fell down from the polymer solution. The destruction of the polymer can be attributed to an irreversible deterioration of the film by the formation of electroinactive polymer films on the electrode surface. The dependence of the current peak, $I_{\mathrm{p}}$, vs. $v^{1 / 2}$ and potential peak, $E_{\mathrm{p}}$, vs. $v^{1 / 2}$, in blank solution, is linear, respectively. So, the redox process in the polymer film is irreversible.

\section{Potentiostatic Current Transient}

The potentiostatic current transient of working electrodes in solution provides relevant information about the coating growth kinetics. The current-time curves for the polymerizaton of P3MT by potential step are shown in Figure 3. The general feature of these curves is similar to those reported for other deposited conducting polymers. ${ }^{25,26}$ Following the initial spike, the current falls to a minimum followed by a practically linear 


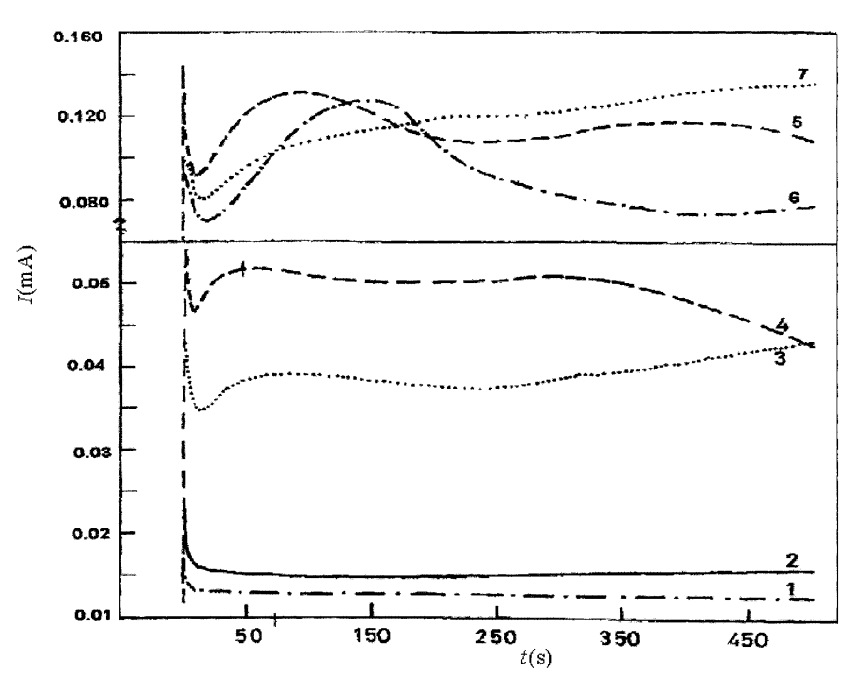

Figure 3. Potentiostatic polymerization carried out at different potentials for $500 \mathrm{~s}$ on $\mathrm{Au}$ in $0.1 \mathrm{M} 3 \mathrm{MT}+0.1 \mathrm{M} \mathrm{LiClO}_{4}$ in acetonitrile (1) 0.800 , (2) 0.900, (3) 1.000, (4) 1.100, (5) 1.275, (6) 1.300, and (7) $1.350 \mathrm{~V} / \mathrm{Ag}$.

with $t^{2}$ current increase. A current maximum can be detected in the time range proceeding to the continuous current increase. This current maximum can be caused by either overlap or cessation of nuclei growth, or both. The linear current increase, can be related to the growth of the bulk polymer layer. The complex behavior of this current transient can be assigned to different stages in polymer formation on the substrate. ${ }^{27}$ This feature together with the current cross-over in the first voltammogram during polymer deposition under swept potential control is typical of deposition through a nucleation and growth mechanism. ${ }^{28-30}$ The monomer electrooxidation behaves as a surface-controlled reaction as it is inferred from the current transient dependence of the potential.

The processes involved in the initial spike are considered to be mainly monomer oxidation, intermediate adsorption and polymer deposition. Polymer deposition may proceed through random adsorption on the bare substrate as well as growth on the polymer nuclei. For a relatively low deposition potential $(0.9-1.1 \mathrm{~V})$, a limited number of nuclei grows independently without any overlap occurring. This free growth results in a current increase. As time goes on, the nuclei become bigger and begin to overlap with each other and, in the advanced stage of P3MT growth a strong potential dependence is found. This current time behavior is not very well resolved, only the very initial part of the current transient is being integrated.

The theoretical current-time relationship depends on both the kinetics of the nucleation process (instantaneous or progressive) and the geometry of the growing nuclei 2D islands or 3D clusters. According to the nucleation model, two possible mechanisms account for this $i-t$ behavior, progressive 2D nucleation and growth in the form of equation:

$$
i=\frac{\pi Z M h A N_{\mathrm{o}} k^{2} t^{2}}{\rho}
$$

and instantaneous 3D nucleation and growth in the form of equation:

$$
i=\frac{2 \pi Z M^{2} F N_{\mathrm{o}} k^{3} t^{2}}{\rho}
$$

Where $M$ is the molecular weight, $N_{\mathrm{o}}$ is the number of available nucleation sites, $k$ is the growth rate constant, $A$ is the nucleation rate constant, $\rho$ is the density of the deposited material, $Z$ is the charge transferred from each monomer unit, $h$ is the height of the 2D disc shaped nucleus, and $F$ is the Faraday constant.

Since both cases predict the same time dependence of the current, the exact mechanism cannot be decided unequivocally from this behavior alone.

In the case of 2D island involving overlap growing under kinetic control, the current transient for the progressive nucleation in a non-dimensional form is given by:

$$
\frac{I}{I_{\mathrm{m}}}=\left(\frac{t}{t_{\mathrm{m}}}\right)^{2} \times \exp \left[\frac{2}{3} \frac{\left(t_{\mathrm{m}}^{3}-t^{3}\right)}{t_{\mathrm{m}}^{3}}\right]
$$

The parameters $t_{\mathrm{m}}$ and $I_{\mathrm{m}}$ are the coordinates of the current maximum. These parameters are potential dependent through the rate constant $A k^{2}$. The product $I_{\mathrm{m}} \times t_{\mathrm{m}}$, however, is independent of potential. In the case of 3D cluster growing under kinetic control for the instantaneous nucleation, the non-dimensional form is given by:

$$
\frac{I^{2}}{I_{\mathrm{m}}^{2}}=\frac{1.9542}{t / t_{\mathrm{m}}} \times\left[1-\exp \left(-1.2465 \frac{t}{t_{\mathrm{m}}}\right)\right]^{2}
$$

The parameters $t_{\mathrm{m}}$ and $I_{\mathrm{m}}$ are the coordinates of the current maximum. For this case the product $I_{\mathrm{m}} t_{\mathrm{m}}$ is strongly dependent with the potential, and $I_{\mathrm{m}} \times t_{\mathrm{m}}^{2}$ is constant.

Figure 4 shows the non-dimensional plot of the experimental data compared with the theoretical curves for instantaneous and progressive nucleation (eqs 3 and 4). As can be seen, there is better correspondence between the experimental data and the theoretical relationship accounting for instantaneous nucleation and growth of $3 \mathrm{D}$ clusters than the $2 \mathrm{D}$ progressive nucleation.

From a set of values for the transients and the $t^{2}$ current dependence we have suggested that the transients represent a 3D instantaneous growing. In the advanced stage of P3MT growth, the linear current transient is strongly potential depending, and this behavior, can be explained considering the polymer formation as a 


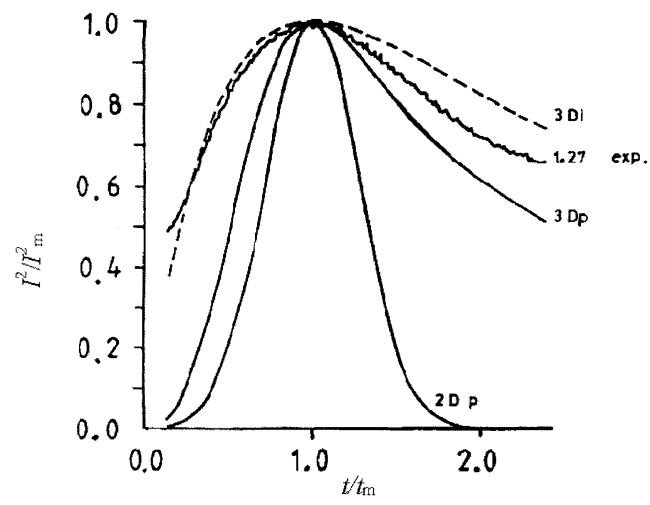

Figure 4. Non-dimensional plots of $I^{2} / I_{\mathrm{m}}^{2} v s$. $\quad t / t_{\mathrm{m}}$ plots theoretical curve for $2 D_{\mathrm{p}}$ (progressive nucleation), $3 D_{\mathrm{p}}$ (progressive nucleation), $3 D_{\mathrm{i}}$ (instantaneous) and experimental date for $E=$ $1.27 \mathrm{~V} / \mathrm{Ag}$.
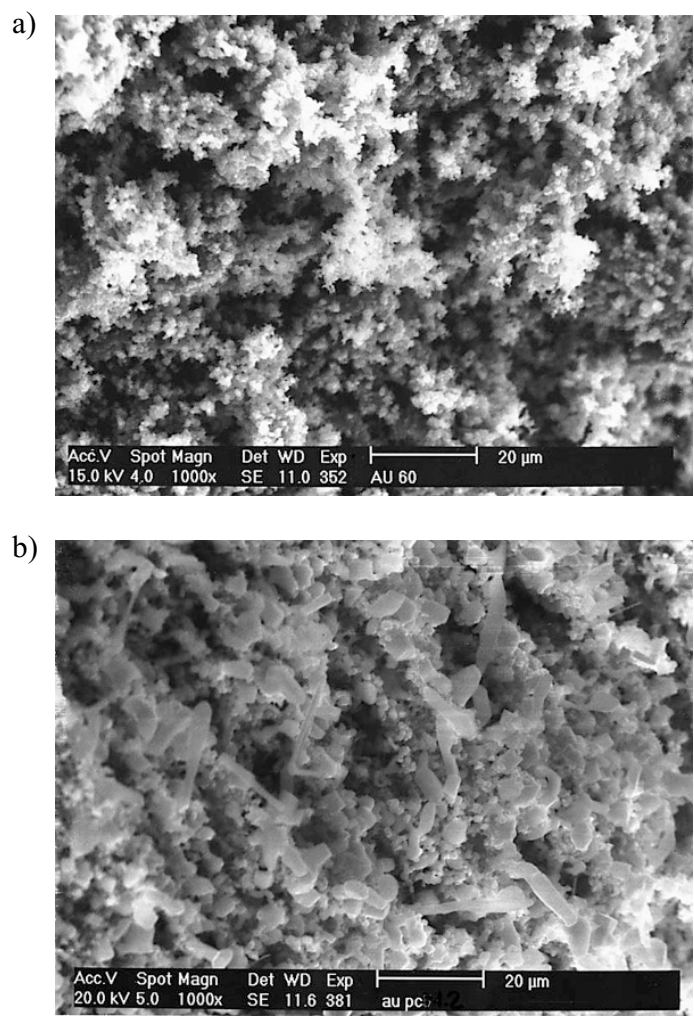

Figure 5. SEM micrographs of the polymer growth by a) cyclic voltammetry during 5 cycles b) Potentiostatic method $(E=$ $1.2 \mathrm{~V} / \mathrm{Ag}, t=500 \mathrm{~s})$.

progressive nucleation on substrate sites, followed by the growth of independent linear chains under chargetransfer control. ${ }^{31}$

\section{Structure}

The morphology for P3MT changes with the experimental conditions of the electrodeposition and with the nature of the substrate. The surface of polymer is rough, presented compact and homogeneous structure, obtaining round grains with little grains inside. If the P3MT was grown by potentiostatic method (Figure 5 b), the film was homogeneous but the porosity was

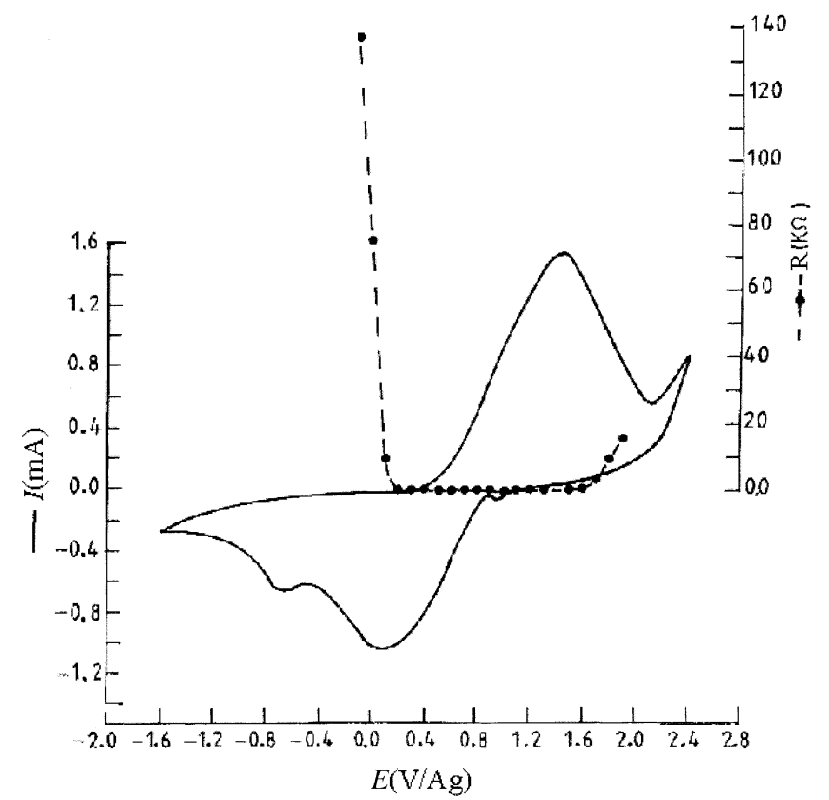

Figure 6. Cyclic voltammogram of $\mathrm{P} 3 \mathrm{MT}$ in $\mathrm{PC}+0.5 \mathrm{M}$ $\mathrm{LiClO}_{4}$ and the resistance profile as a function of applied electrochemical potential.

higher than in the samples grown by cyclic voltammetry, which presented branching with extended grains.

\section{Resistance}

Figure 6 shows the dependence of the resistance of P3MT as a function of the electrochemical potential. The resistance measurements were carried out at $25^{\circ} \mathrm{C}$ in $\mathrm{PC}+0.5 \mathrm{M} \mathrm{LiClO}_{4}$.

The polymer film is insulating at sufficiently negative $(0.1 \mathrm{~V})$ or positive $(1.6 \mathrm{~V})$ electrochemical potentials. These results are different when the measurements were carried out in $1 \mathrm{M} \mathrm{H}_{2} \mathrm{SO}_{4}$. The window for the potential is $(0.5$ to $1.1 \mathrm{~V})$ for the P3MT grow in the same conditions. If the film is grown potentiodinamically, the range changes ( 0.7 to $1.1 \mathrm{~V})$.

The change in resistance is generally of the order of $10^{4}$, although this value depends of film thickness. The minimum resistance for the P3MT is similar to polyaniline, or poly(o-toluidine), thus, the P3MT can be considered to be good conductor under these conditions. It seems that the electrochemical activity of the polymer film occurs mainly at potentials between $(0.1$ to $1.6 \mathrm{~V})$ in $\mathrm{PC}+0.5 \mathrm{M} \mathrm{LiClO}_{4}$ and (0.5 to 1.1$)$ in $1 \mathrm{M} \mathrm{H}_{2} \mathrm{SO}_{4}$ solution. The polymer has the ability to drive redox reactions whose redox equilibrium potentials are within this range. Couples whose equilibrium potentials are outside this range are inhibited.

\section{Geometric Considerations Based on Diffusion Limited Current Measurements}

The conducting polymer films of interest are made purposely much thicker that a monomolecular layer. 
The deposition is therefore a macrogrowth occurring in three dimensions. ${ }^{32}$ These polymers, in general, show disordered rough structures with some amorphous crystalline domains.

An important question arise when we consider the growth of a polymer structure. It is realistic to describe the branched polymer surface by means of a classical geometric model or non. Formerly an answer to this question can be given by studying the correlation between two quantities, one proportional to the volume $\mathrm{V}$ of the deposited polymer film and the other proportional to its surface area A.

This correlation was studied in the case of P3MT growth at $1.5 \mathrm{~V} v s$. Ag on graphite in PC. A typical voltammogram runs at $0.05 \mathrm{~V} \mathrm{~s}^{-1}$ for P3MT exhibits the pair of conjugated current peaks and the diffusional limiting currents related to the $\left[\mathrm{Fe}(\mathrm{CN})_{6}\right]^{4-} /$ $\left[\mathrm{Fe}(\mathrm{CN})_{6}\right]^{3-}$ redox couple.

The potentiostatic current transient related to the

$$
\mathrm{Fe}(\mathrm{CN})_{6}^{-4} \leftrightarrow \mathrm{Fe}(\mathrm{CN})_{6}^{-3}+1 \mathrm{e}^{-}
$$

reaction at the polymer electrode was at potentials in which the test reaction is under diffusion control. For a non-stationary electrochemical reaction under diffusion control, layer thickness with time and the gradient for the diffusing species decreases. When the process involves a soluble reaction species in solution diffusing under semi-infinite linear conditions towards a planar electrode, the non-stationary diffusion controlled current is given by Cottrell equation. ${ }^{33}$

$$
I=n F C(D / \pi t)^{1 / 2}
$$

Where $C$ and $D$ are bulk concentration and the diffusion coefficient of the electroactive species, and $n$ and $F$ have the usual meaning.

Thus, the polymer coated electrode was stepped from -0.225 to $0.200 \mathrm{~V} v s$. Saturated calomel electrode (SCE) in order to the eq 5 proceeds. Prior to these experiments, blanks in $0.5 \mathrm{M} \mathrm{H}_{2} \mathrm{SO}_{4}$ were run to discriminate the proper polymer electrooxidation current components. A different situation arises for the case of diffusion towards fractal surfaces. The time dependence of the diffusion current becomes more complex, being $I$ proportional to $t^{-\beta}$. The rapid $i-t$ transient is shown in Figure 7. Current transient data were displayed as $\log I$ vs. $\log t$ plots (Figures 8 and 9).

These plots show two linear responses, which fulfil the following proportionality ${ }^{34}$ between the current and $\beta$,

$$
I \cong t^{-\beta}
$$

with $\beta=(0.77,0.74,0.73,0.69)$ for $t<1 \mathrm{~s}$ and $\beta=(0.47,0.48,0.50,0.50)$ for $t>1 \mathrm{~s}$. It is known that, for a diffusion-controlled electrochemical reaction

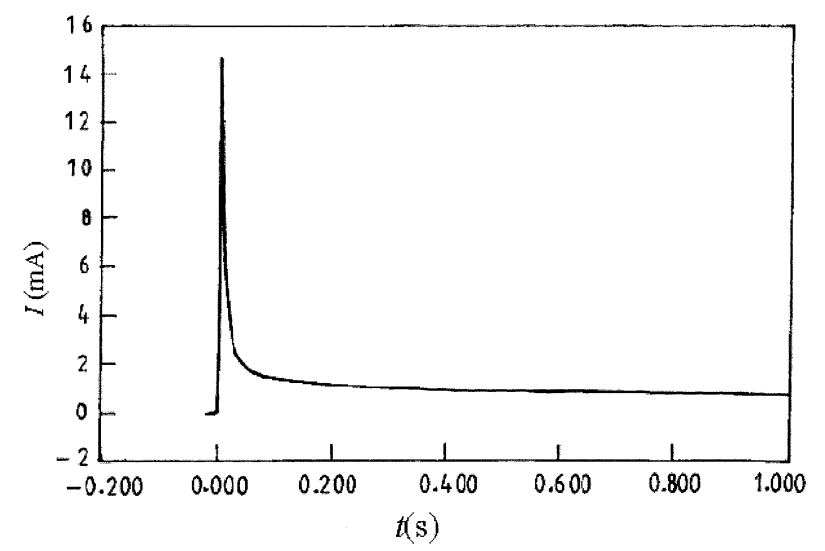

Figure 7. Pontentiostatic transient for $\left[\mathrm{Fe}(\mathrm{CN})_{6}\right]^{4-} /\left[\mathrm{Fe}(\mathrm{CN})_{6}\right]^{3-}$ for P3MT in $0.5 \mathrm{M} \mathrm{H}_{2} \mathrm{SO}_{4}$.

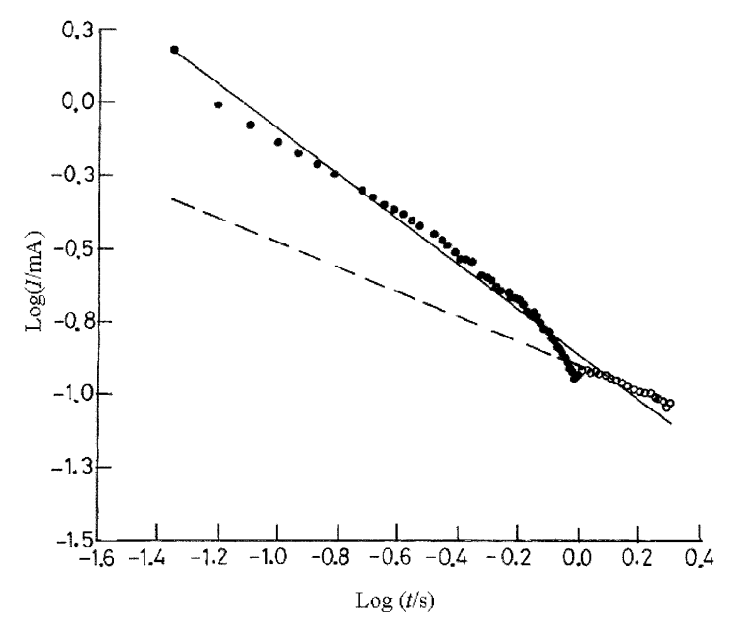

Figure 8. $\log I v s . \log t$ for P3MT: $\beta=0.77$ for $t<1 \mathrm{~s}$ and $\beta=0.42$ for $t>1 \mathrm{~s}$.

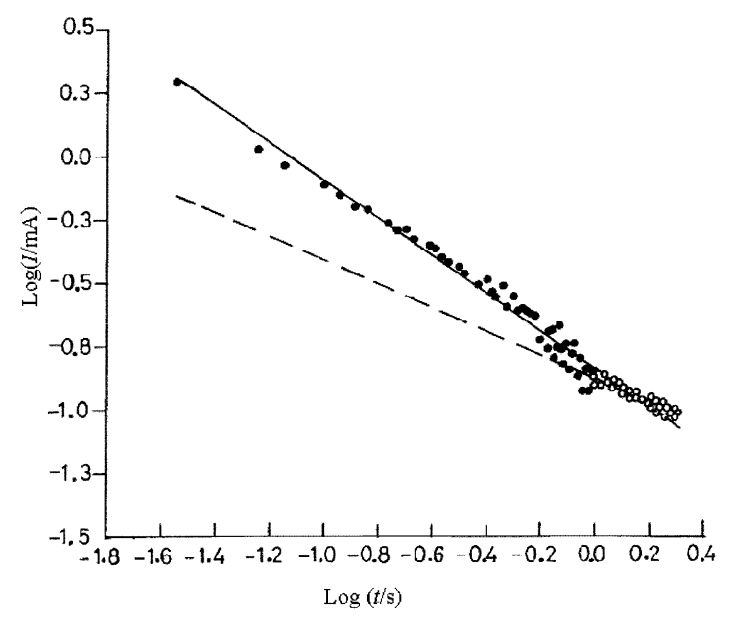

Figure 9. $\log I$ vs. $\log t$ for P3MT: $\beta=0.74$ for $t<1 \mathrm{~s}$ and $\beta=0.47$ for $t>1 \mathrm{~s}$.

involving soluble species in solution, there is a relation between $\beta$ and the fractal dimension of the electrode surface $D_{s}$, this is given by 35,36 :

$$
\beta=\left(D_{\mathrm{s}}-1\right) / 2
$$

From eq 6 and the $\beta$ values, one obtains $D_{\mathrm{s}}=2.5 \pm 0.1$ for $t<1 \mathrm{~s}$ and $D_{\mathrm{s}}=2.0 \pm 0.1$ for $t>1 \mathrm{~s}$. According 


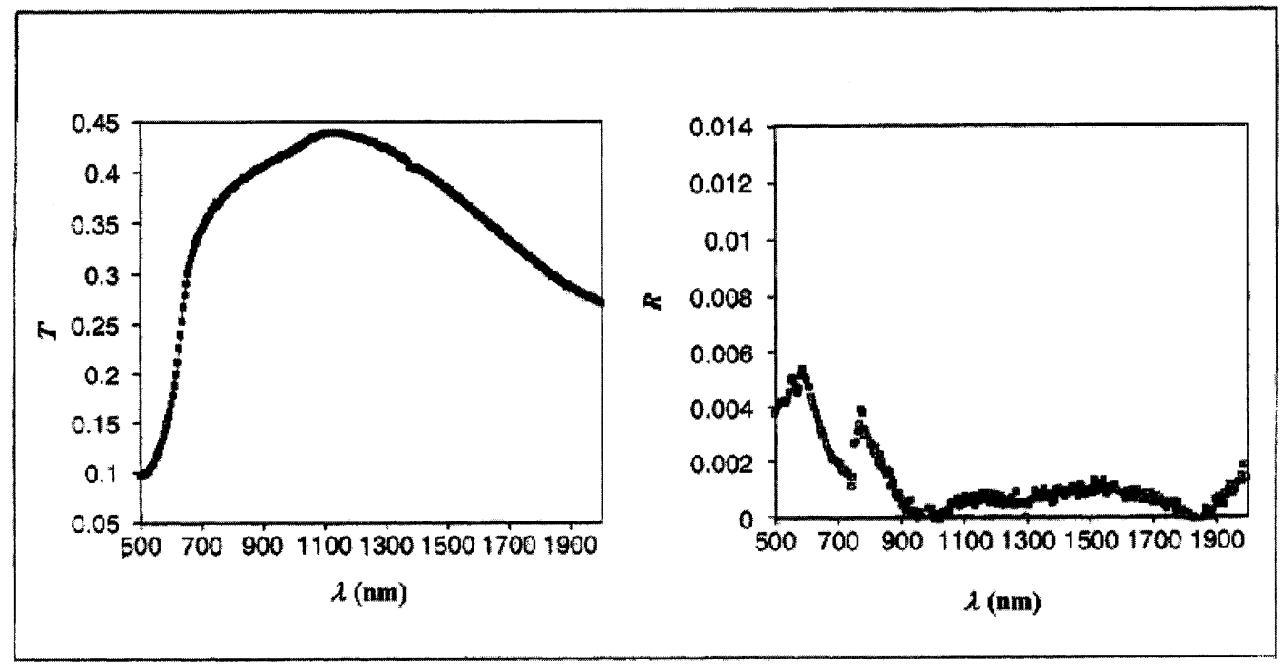

Figure 10. Transmittance and reflectance spectrum $v s . \lambda$.

to the results for $t<1 \mathrm{~s}$ the $D_{\mathrm{s}}=2.5 \pm 0.1$ behaves as a self-affine fractal surface the corresponding diffusion layer tickness scales the large roughness of the polymer coated-electrode surface. Finally for $t>1 \mathrm{~s}$, the $\log I$ vs. $\log t$ plot approaches the conventional slope $\beta=0.5$; i.e., when the diffusional layer thickness becomes larger than the size of the largest irregularities, the electrode surface behaves as a smooth surface, then the surface approaches apparently the behavior of an Euclidean surface.

\section{Optical Properties}

A neutral polymer contains alternate single and double bonds along its chain, a large band gap between $\pi$ and $\pi^{*}$ levels indicates that low population of electrons can jump from the occupied $\pi$ band to the unoccupied $\pi^{*}$ band. So the conductivity of a neutral polymer is low. Polymeric oxidation generates empty polaronic and bipolaronic bands in the midgap. Since the new bands can house electrons, increasing amounts of electrons can jump between the valence band and the new polaronic and bipolaronic band. The probability of the jumps increases the number of carriers (electrons and holes) and therefore the conductivity of the polymer layer increases. The charge on the polymer chain is believed to be mobile, moving along the conjugation of the backbone of the polymer.

Reflectance and transmittance spectra of a P3MT film are shown in Figure 10. These measurements and the film thickness allowed us to determine the absorption coefficient $\alpha$ and the refraction index $\eta$ for each wavelength by using a modes that takes into account multiple reflection, coherent in the film and incoherent in the substrate (considering ITO as a substrate), as well as, through a minimisation computer programme based on the Newton-Raphson method. ${ }^{37}$ Figure 11 shows a

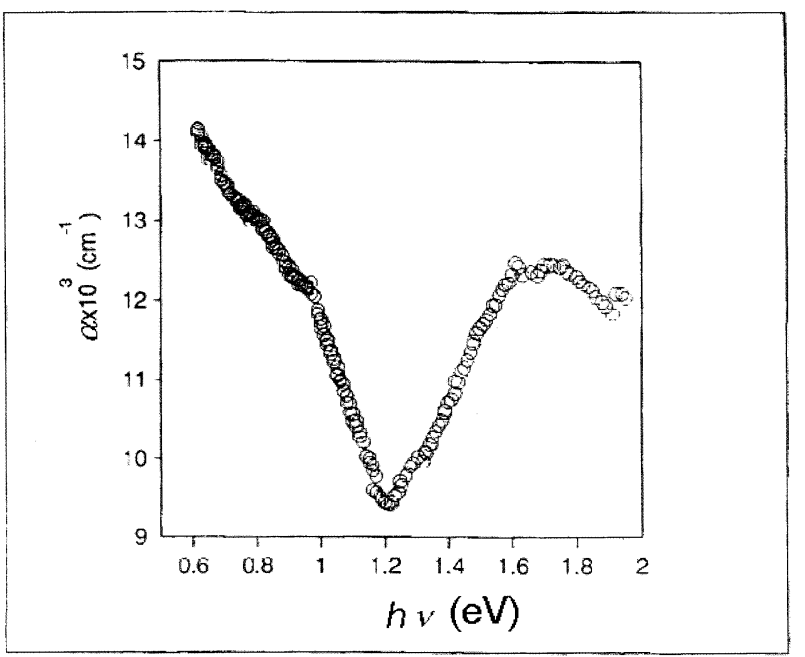

Figure 11. Absorption coefficient $v s . h v$.

typical absorption coefficient spectrum, $\alpha(h v)$. For energies comprised between 0.6 and $1.2 \mathrm{eV}, \alpha$ decreases, this behavior can be attributed to the absorption in IR by free carrier.

Between $1.2-1.5 \mathrm{eV}, \alpha$ increases, this absorption region can correspond to a direct or an indirect gap transition. In this region the conducting substrate does not absorb. All samples present qualitatively analogous adsorption coefficient. The absorption coefficient is related to the photon energy by ${ }^{38}$ :

$$
(\alpha h v)^{2 / n}=B\left(h v-E_{\mathrm{g}}\right)
$$

where $h$ is the Plank's constant, $v$ is the frequency of the incident radiation, $E_{g}$ is the band gap, $B$ is a constant, and $n$ is a parameter that takes the value 1 for direct or for indirect transition.

Figure $12 \mathrm{~b}(\alpha h v)^{2} v s . h v$ shows that absorption evaluated between 1.25 and $1.65 \mathrm{eV}$ yields a linear plot with a value of $n=1$, indicating that transition to be direct in P3MT. From the intercept on the abscise a value for 


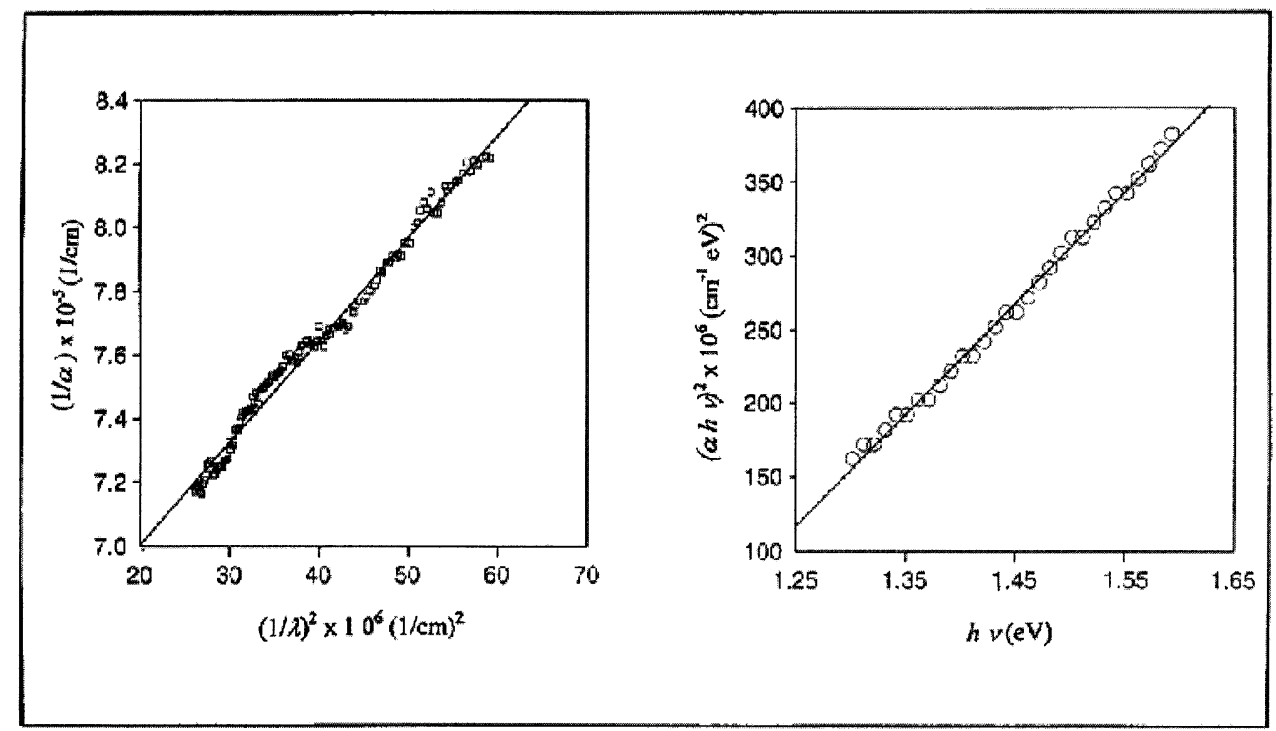

Figure 12. a) Transport properties. $1 / \alpha v s .1 / \lambda^{2}$. b) Fit of first direct band-gap energy.

Table I. Transport properties and band gap energy of P3MT

\begin{tabular}{|c|c|c|c|c|}
\hline $\begin{array}{l}\text { SAMPLE } \\
\text { Growth }\end{array}$ & $\sigma / \Omega^{-1} \mathrm{~cm}^{-1}$ & $\mu / \mathrm{V}^{-1} \mathrm{~cm}^{2} \mathrm{~s}^{-1}$ & $\begin{array}{c}\text { Free charge } \\
\text { carriers }\end{array}$ & $E_{\mathrm{g}} / \mathrm{eV}$ \\
\hline $\begin{array}{l}\text { Potentiodynamic } \\
v=50 \mathrm{mV} \mathrm{s}^{-1} \\
(-0.4,1.8 \mathrm{~V} / \mathrm{Ag})\end{array}$ & 113.54 & 0.026 & $2.7310^{22}$ & 1.02 \\
\hline $\begin{array}{l}\text { Potentiostatic } \\
E=1.5 \mathrm{~V} / \mathrm{Ag}\end{array}$ & 3415.00 & 0.335 & $6.4410^{22}$ & 0.98 \\
\hline $\begin{array}{l}\text { Potentiostatic } \\
E=1.8 \mathrm{~V} / \mathrm{Ag}\end{array}$ & 133.76 & 0.049 & $1.7410^{22}$ & 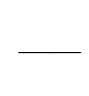 \\
\hline $\begin{array}{l}\text { Potentiostatic } \\
E=2.0 \mathrm{~V} / \mathrm{Ag}\end{array}$ & 75.45 & 0.012 & $3.9310^{22}$ & 1.08 \\
\hline
\end{tabular}

the $E_{g}$ of $1.08 \mathrm{eV}$ was obtained. The indirect transition and forbidden direct transitions are not obtained in this region for none of samples analysed. All samples presented the same behavior, and optical band gap comprised between $0.98-1.08 \mathrm{eV}$ were evaluated.

Another fundamental absorption is the absorption by free charge carrier, according to the equation:

$$
\frac{1}{\alpha}=\frac{\varepsilon_{0} n c}{\sigma}+\frac{4 \pi^{2} \varepsilon_{0} c^{3} n m^{* 2} \mu^{2}}{\sigma q^{2} \lambda^{2}}
$$

Where $\varepsilon_{0}$ is the dielectric constant, $\eta$ is the refraction index, $c$ the light speed, $m^{*}$ the effective mass, $q$ the charge of the electron, $\sigma$ the conductivity and $\mu$ the mobility. In the far IR the $1 / \alpha v s .1 / \lambda^{2}$ (Figure 12a) is studied. The linear behavior suggests that the polymer film show the absorption by free charge carrier. We can obtain the transport properties $\sigma, \mu$, and the free charge carrier. These results for different polymer films are shown in Table I.

The conductivity $\sigma$, changes between 75.5 and 3415 $\Omega^{-1} \mathrm{~cm}^{-1}$. The growth method is determinant for the value of the transport properties. If the growth method is the cyclic voltammetry, mobility $\mu$, and free charge carriers are half-way of those values obtained when the polymer is potentiodinamically generated. When the potential growth is very large $(1.8-2.0 \mathrm{~V})$, the transport properties did not improve. The band gap of these polymeric materials in oxidized state was $\approx 1 \mathrm{eV}$ for all samples without affecting him the growth method. This is a narrow value in comparison with the same polymer in neutral state. All polymer films we have studied have a lot of free charge carriers, almost independent of the growth method. This characteristic confers conductive properties to the material.

\section{CONCLUSION}

Films of P3MT grown by the potentiostatic and potentiodynamic method show good adherence on the conducting substrate.

The potentiostatic current transient suggests that, in 
the first stage of P3MT growth, a 3D instantaneous nucleation and growth can happen. In the macrogrowth state the polymer formation is strongly potential depending, and the polymer growth can be explained as a progressive nucleation on substrate sites followed by the growth under charge-transfer control. The morphology for P3MT changes with the experimental conditions. The films were homogeneous with open structures for potentiostatic method and branched with extended grains for potentiodynamic method. The macrogrowth shown disordered rough structures. For the ferro/ferri reactions, the difusion layer thickness probes the large scale surface roughness, as a log (diffusional current) $v s$. $\log$ (time) plot exhibits a certain linear range with an anomalous slope, which is compatible with fractal dimension $D_{\mathrm{s}}=2.5$ for $t<1 \mathrm{~s}$ behaves as a self-affine fractal surface and $D_{\mathrm{S}}=2.0$ for $t<1 \mathrm{~s}$. The band gap value $\approx 1 \mathrm{eV}$ was obtained for all samples analysed in oxidised state and all polymer films studied had a lot of free charge carriers having these materials good conductive characteristics.

\section{REFERENCES}

1. H. Shirakawa, E. J. Louis, A. G. MacDiarmid, C. K. Chiang, and A. G. Heeger, J. Chem. Soc. Chem. Comm., 578 (1977).

2. C. K. Chiang, Y. W. Park, A. J. Heeger, H. Shirakawa, E. L. Louis, and A. G. MacDiarmid, Phys. Rev. Lett., 39, 1098 (1977).

3. C. K. Chiang, M. A. Druy, S. C. Gau, and A. J. MacDiarmid, J. Am. Chem. Soc., 100, 1018 (1978).

4. A. Kitani, M. Kaya, and K. Sasaki, J. Electrochem. Soc., 133, 1069 (1986)

5. A. F. Díaz, W.-Y. Lee, J. A. Logan, and D. C. Green, J. Electroanal. Chem., 109, 377 (1980); ibid., 129, 115 (1981). T. F. Otero, R. Tejada, and A. S. Elola, Polymer, 28, 651 (1987).

6. G. Tourillon and F. Garnier, J. Electronal. Chem., 135, 173 (1982).

7. M. Kabasakaloglu, T. Kiyak, H. Toprak, and M. L. Aksu, Appl. Surf. Sci., 152, 115 (1999).

8. N. Sally, N. Hoier, and S.-M. Park, J. Phys. Chem., 96, 5188 (1992)

9. F. Garnier, G. Tourillon, M. Gazard, and J. C. Dubois, J. Electroanal. Chem., 148, 299 (1983)

10. J. Roncali, M. Lemaire, R. Garrean, and F. Garnier, Synth. Met., 18, 139 (1987).

11. A. Czerwinski, H. Zimmer, Ch. Van Pham, and H. B. Mark, Jr., J. Electrochem. Soc., 132, 2669 (1985).

12. S. Hotta, T. Hosaka, and W. Shimotsuna, Synth. Met., 6, 69 (1983).
13. A. O. Patil, A. J. Heeger, and F. Wuld, Chem. Rev., 88, 183 (1988).

14. C. Hso, Ng Sc. Progress in Polymer Sci., 23, 1167 (1998).

15. A. Yassar, J. Roncali, and F. Garnier, Macromolecules, 22, 804 (1989).

16. R. H. J. Schmitz and K. Juttner, Electrochim. Acta., 44, 1627 (1999).

17. P. Novak, K. Muller, K. S. V. Santhanam, and O. Hass, Chem. Rew., 97, 207 (1997).

18. L. W. Shacklette, M. Maxfied, S. Gloud, J. F. Wolf, T. R. Jow, and R. H. Banghman, Synth. Met., 18, 611 (1987).

19. E. M. Genies, M. Lapkowski, C. Santier, and E. Vieil, Synth. Met. 18, 631 (1985).

20. K. Kaneto, T. Shiraishi, and K. Yoshino, Jpn. J. Appl. Phys., Part 2, 24, L107 (1985).

21. T. F. Otero, Mod. Aspects Electrochem., 33, 307 (1999).

22. A. R. Hillman and E. F. Mallen, J. Electroanal. Chem., 220, 351 (1987).

23. M. Gholamian, T. N. S. Kuman, and A. Q. Contractor, -Proc. Indian Acad. Sci. Chem. Sci., 97, 457 (1986).

24. P. Ocón and P. Herrasti, New J. Chem., 16, 501 (1992).

25. A. J. Downard and D. Pletcher, J. Electroanal. Chem., 206, 139 (1986)

26. L. L. Miller, B. Zinger, and Q. X. Zhon, J. Am. Chem. Soc., 109, 2267 (1987).

27. S. Asavapiriyanont, G. K. Chandler, G. A. Gunawardena, and D. Pletcher, J. Electroanal. Chem., 177, 229 (1984).

28. M. Fleischmann and H. R. Thirsk, in "Advances in Electrochemistry and Electrochemical Engineering," P. Delahay, Ed., Wiley Interscience, New York, N.Y., 1963, vol. 3, p 123.

29. E. B. Budevski, in "Comprehensive Treatise of Electrochemistry,” B. E. Conway, J. O’Bockris, E. Yeager, S. Um. Khan, and R. E. White, Ed., Plenum Press, New York, N.Y., 1983, vol. 7, p 339.

30. J. A. Harrison and H. R. Thirsk, in "Electroanalytical Chemistry," A. J. Bard, Ed., Marcel Dekker Inc., New York, N.Y., 1971, vol. 5, p 67.

31. K. Bode, V. Tsokiva, and J. W. Sultze, Electrochim. Acta, 37, 2249 (1992)

32. E. Bosco and S. Rangarajian, J. Electroanal. Chem., 143, 213 (1982).

33. L. Nyikos and T. Pajkossy, Electrochim. Acta, 31, 1347 (1986); ibid., 34, 171 (1989).

34. P. Ocón, P. Herrasti, J. M. Vara, L. Vázquez, R. C. Salvarezza, and A.J. Arvia, J. Phys. Chem., 98, 2418 (1994).

35. T. Pajkossy and L. Nyikos, Electrochim. Acta, 34, 171 (1989).

36. T. Pajkossy, J. Electroanal. Chem., 30, 1 (1991).

37. F. Abeles, in "Methods for Determining Optical Parameters of Thin Films; Progress in Optics,” E. Wolf, Ed., North-Holland, Amsterdam, 1963, pp 619-622.

38. K. V. Shalímova, in "Física de Los Semiconductores", Mir, Ed., Moscú, 1975, pp 265-270. 